Research Article

\title{
Suitability Investigation of Recycled Concrete Aggregates for Concrete Production: An Experimental Case Study
}

\author{
Woubishet Zewdu Taffese \\ Department of Civil Engineering, Aalto University, P.O. Box 12100, FI-00076 Aalto, Finland \\ Correspondence should be addressed to Woubishet Zewdu Taffese; woubishet.taffese@aalto.fi
}

Received 16 April 2018; Revised 31 August 2018; Accepted 9 September 2018; Published 30 September 2018

Academic Editor: Flora Faleschini

Copyright (c) 2018 Woubishet Zewdu Taffese. This is an open access article distributed under the Creative Commons Attribution License, which permits unrestricted use, distribution, and reproduction in any medium, provided the original work is properly cited.

In developing countries, construction and demolition waste (CDW) is disposed to landfill, causing social, environmental, and economic crises. In these nations, CDW exponentially increase due to their rapid economic growth, industrialization, and urbanization. This paper aims to examine the possibility of recycling concrete waste for production of new concrete in Ethiopia. Physical and mechanical characteristics of recycled concrete aggregate (RCA) acquired from concrete waste are thoroughly examined. Though the RCA exhibited relatively lesser performance compared with the natural coarse aggregate (NCA), it reveals the same properties as of normal-weight aggregates in several instances. The performance of concrete specimens which employ RCA up to $20 \%$ is evaluated from workability, strength, and permeability aspects. The utilization of RCA slightly affects the workability and the water permeability properties of the concretes. Replacement of $10 \%$ of the NCA by the RCA enhances the compressive strength of the hardened concrete by $8 \%$. The difference between the splitting tensile strength of the concretes which employ RCA and conventional aggregates is trivial. Generally, this work demonstrates the practicability of concrete waste recycling to produce new concrete or construction materials in Ethiopian context.

\section{Introduction}

Solid waste volume is increasing globally at an alarming rate. Today, the world is generating about 1.3 billion tonnes of solid waste per annum and expected to be 2.2 billion tonnes by 2025 [1]. The construction industry is one of the sectors around the globe that generate huge amount of waste, both in volume and weight [2]. The construction and demolition waste (CDW) comprises heterogeneous mix of materials in which inert materials represent the largest portion that accounts for $40 \%$ to $85 \%$ [3]. Among the intermaterials, the biggest fraction is concrete waste. Though the construction industry generates large quantity of waste, there has been a growing interest in the utilization of non-CDW waste generated from various processes in producing construction materials to achieve potential benefits. To mention few cases, there are studies which demonstrate the practicability of producing concrete from waste materials of carpet fiber and palm oil fuel ash [4], textile effluent sludge [5], scrap tire rubber $[6,7]$, electric arc furnace slag $[8]$, and fly ash $[9,10]$.
There are also studies that reveal the benefits of agro wastes, e.g., bagasse and cotton stalk fibers, in producing building materials $[11,12]$.

Waste generated by the construction industry in emerging countries is considerably high due to inefficient construction and waste management practices. CDW in these nations will exponentially increase further since the construction activity will flourish as a result of rapid economic growth, industrialization, and urbanization. In addition, as part of urbanization process, old infrastructure which unfulfilled the current functional or structural requirements is demolished thus generating more and more CDW. This will further aggravate the existing capacity constraints in managing waste. Presently, the majority of CDW in several developing countries is disposed primarily in landfills, causing social, environmental, and economic problems. For the adverse effect of CDW on health and environment as well as with ever-increasing demand for constructible land, disposing the CDW in landfills would not be a prior alternative. 
The global demand for natural aggregates for production of concrete is projected to grow by an average of $7.7 \%$ per year to reach 66.2 billion metric tons by 2022 [13]. A significant portion of this demand is driven by developing countries as a result of their rapid industrialization and urbanization growth. Utilization of recycled aggregates from concrete waste for new construction can significantly help us to conserve natural resources and reduce waste disposal and haul, which in turn gains both economic and environmental benefits. Recycled concrete aggregates were used in developed countries as a replacement to natural coarse aggregates for stabilizing the base course of road constructions, leading to save the natural reserve for generations to come. Though incorporation of recycled aggregates from CDW remarkably enhances the ecological footprint of concrete, the utilization of RCA in construction activities in several developing countries is yet limited. The main reason for this is that lack of confidence or knowledge on how the concrete waste can be recycled into new concrete or other construction materials.

Ethiopia is one of the developing countries in Africa where recycling of CDW is unexercised. The country, at a recent time, is undergoing a swift economic boost which has been accredited mainly to construction boom. The unprecedented success in the construction sector increases the demand for natural aggregates. It also causes for generation of huge amount of CDW, creating shortage of land for infrastructure development since CDW in Ethiopia is normally disposed to landfill sites [14]. If appropriate and timely interventions are not taken, the observed problems will be further aggravated, causing social, environmental, and economic crises. Hence, practicability investigation of RCA for use in concrete production or construction materials in context of Ethiopia is exceptionally requiring immediate attention.

The overall objective of this work is to examine the possibility of recycling concrete waste for production of new concrete in Ethiopia. The specific objectives of this work are twofold: (i) to investigate the suitability of RCA for new concrete production by characterizing their physical and mechanical properties and (ii) to evaluate the performance of concrete specimens which partially employ RCA from workability, strength, and permeability aspects. As there are no in-depth studies found in literatures, the findings of this research will provide critical insights into the utilization of RCA for producing concrete products in Ethiopian context.

The structure of this paper is as follows. In Section 2, the recent advances in recycling concrete waste to produce new concrete and construction materials are presented. It also discusses the need for investigating the suitability of RCA in developing countries for contributing towards sustainability in construction industries. The materials and methods that are utilized to investigate the possibility of recycling concrete waste into concrete elements are discussed in Section 3. In Section 4, the core results and their analyses are explained in detail. It presents the possibility of utilizing RCA for new concrete structure through characterization of their physical and mechanical properties. This section also elaborates the performance of the concrete that utilized RCA from workability, strength, and permeability perspectives. Finally, conclusions of the work are presented in Section 5.

\section{Recent Advances in Recycling Concrete Waste}

Generation of huge amount of CDW coupled with depletion of natural aggregates calls for utilization of CDW in costeffective and ecofriendly manner. Crushing of concrete waste to produce RCA and reusing it with natural aggregates to create concrete elements has been recognized as one of the most practical and sustainable methods for handling of CDW. Demolished concrete pavements had been utilized for stabilizing road base course during the past few decades. More recently, various studies have been performed to find out how concrete waste can be reused for production of concrete products or structural elements instead of using as road base course material. Özalp et al. [15] investigated the suitability of RCA for manufacturing of different types of concrete products such as ready-mixed concrete, concrete pipe, and concrete kerb. The researchers concluded that, with appropriate sorting, the use of RCA as secondary raw material is practicable for production of various types of concrete elements that fulfill the related standards. Soutsos et al. [16] examined the use of RCA in fabricating concrete building blocks. They claimed that partial replacement of natural aggregates by RCA is feasible to make concrete blocks without notable strength reduction. Hamad and Dawi [17] evaluated the workability and mechanical properties of concrete which employed RCA of various portions. Their evaluation revealed about $10 \%$ average reduction in compressive strength and minimal effect on workability. On the basis of this and other results obtained, the authors concluded that utilization of RCA will bring a positive impact on the concrete construction industry. Poon et al. [18] investigated the performance of low-grade recycled aggregates acquired from a sorting facility of CDW. The properties of this type of aggregates are substantially different from RCA obtained from crushed concrete waste. This is mainly because of the presence of greater amounts of nonconcrete elements such as soil, brick, and ceramic in the sorted construction waste. The findings of their study confirmed that even low-graded recycle aggregates have a capacity to be employed as aggregates for manufacturing precast concrete blocks. Manzi et al. [19] examined the long-term physical and mechanical properties of self-compacting concrete employed up to $40 \%$ RCA. The authors claimed that the properties of the concrete made with RCA are maintained. Even, concrete with RCA yields higher mechanical properties (i.e., elastic modulus, compressive, flexural, and tensile splitting strength) than concrete that utilized only natural aggregates. Etxeberria et al. [20] examined the possibility RCA to produce structural concrete. The examination was focused on the shear behaviour and strength of reinforced concrete (RC) beams which employed RCA. The authors reported that a partial substitution of less than $25 \%$ of RCA hardly influences the shear capacity of RC beams. The study performed by Tošić et al. [21] demonstrated that structural concrete employing 50\% of RCA can yield an optimal solution by taking technical, economic, and environmental 
criteria into consideration. There are also studies which examined the durability aspect of concrete that utilizes RCA exposed to aggressive environments. For instance, Thomas et al. [22] studied water and oxygen permeability of concrete elements which partially and fully employed RCA under accelerated carbonation exposure. The authors reported that, in low water-to-cement $(\mathrm{w} / \mathrm{c})$ ratio, concrete that employs RCA obtains similar durability behaviour with controlling concrete that utilizes NCA. Faleschini et al. [23] performed a reliability-based assessment of carbonation resistance of concrete which utilizes RCA. The authors claimed that w/c ratio is the most governing parameter on carbonation reliability of concrete made with RCA.

It can be noticed from the above studies that significant efforts have been made to recycle concrete waste into different types of concrete products and structural concrete elements. This paves the way towards mitigating the depletion of natural resources as well as the quantity of CDW being landfilled. Though studies showed the potential of RCA for making new structural concrete or construction materials, it is still used mostly as road subbase filler $[16,21,24,25]$. The foremost reason for this fact is the absence or conservative stance of regulations that would allow RCA for the use of concrete production [26]. Only about $1 \%$ of RCA is applied for structural concrete in developed countries [21]. Currently, in many developing nations, the CDW is disposed to landfill instead of being reused and/or recycled. The primary reason for this is that lack of confidence or knowledge on how the concrete waste can be recycled into new concrete or other products. Most of the studies which demonstrate the applicability of RCA for new concrete production are carried out in developed countries. Translating the research findings of those studies directly to developing countries, such as Ethiopia, is impossible since the technology advancement gap between the developed and the developing nations varies considerably. There are only few studies carried out in Ethiopia that investigate the potential use of RCA for new concrete production $[14,27,28]$. More and more in-depth research must be performed with local techniques to build confidence on recycling concrete waste in developing countries, thus contributing towards sustainability in the construction industry.

\section{Experimental Program}

In this section, all the materials utilized in this experimental study are elaborated. Various types of concrete mix compositions with and without RCA are also identified and explained. Finally, the performed tests to characterize the performance of the RCA and the concrete specimens are presented.

3.1. Materials. In this work, natural and recycled aggregates were utilized. The natural aggregates represent coarse and fine. The NCA was crushed stone, whereas the natural fine aggregate (NFA) was river sand. The recycled coarse aggregate was obtained from demolished concrete which was used as a foundation for a universal testing machine (UTM) at the Materials Research and Testing Center (MRTC) of the Ethiopian Institute of Architecture, Building Construction and City Development (EiABC), Addis Ababa University. The age of the original concrete is estimated to be about 55 years old. The age and the type of structural member where the concrete waste comes from may provide some intuition regarding the concrete production method of that time and the strength of the original concrete. It can be presumed that the concrete was mixed and compacted manually and had high strength. However, there is no any document that confirms these thoughts. The concrete waste was broken down into smaller part using a sledgehammer. Later an ordinary hammer was used to breakdown further to separate the coarse aggregates from the old cement paste and to make it in the range approximately between 10 and $35 \mathrm{~mm}$. Messebo cement which is locally produced ordinary Portland cement (CEM I 42.5R) and tap water were used to produce the concrete specimens. No chemical and mineral admixtures were employed.

3.2. Composition of Concrete Mixes. Five kinds of concrete mix compositions were prepared, and based on the target strength class, they are categorized into two: Group I and Group II. Concrete mixes in Group I were designed to achieve a cylinder compressive strength of $25 \mathrm{MPa}$, whereas mixes of Group II were targeted for $35 \mathrm{MPa}$. All the concrete mixes were prepared using weight-based batching system in accordance with ACI 211.1-91 [28]. There are three types of concrete mixes in Group I: Ref-I, RC-10, and RC-10*. Ref-I utilized only natural aggregates, and it is used as a control or reference mix for this group. The concrete mix RC-10 employed RCA with a replacement ratio of $10 \%$ of the overall weight of the NCA. The concrete mix type RC-10* also utilized $10 \%$ of RCA as of RC-10. The difference is the applied procedures during designing the concrete mixes. In the case of RC-10, the concrete mix was designed to achieve a targeted strength class by considering the properties of the natural aggregates. Then, $10 \%$ of the required weight of the NCA to produce the desired concrete was replaced by the RCA. This means that the proportions of all the mix ingredients, except the coarse aggregates, of RC-10 are identical with that of Ref-I. However, in the case of RC-10*, the physical properties of the RCA were considered during the concrete mix design. The property value of the blended coarse aggregate (BCA) was estimated by assuming that the property values of NCA and RCA influence the BCA proportionally, as described by Equation (1). So, all the required properties to design the concrete mix were computed according to Equation (1). Group II entails two kinds of concrete mixes: Ref-II and RC-20. Ref-II employed natural aggregates, and it is the control mix of this group. RA-20 employed $20 \%$ of the RCA as a partial replacement of the NCA. The w/c ratios of the concrete mixes under Group I and Group II were 0.61 and 0.55 , respectively. All the specimens were casted in steel cylinder moulds of size $\varnothing=150 \mathrm{~mm}$ and height $=300 \mathrm{~mm}$ for compressive and splitting tensile strength tests and $100 \mathrm{~mm}$ diameter disc with a length of $50 \mathrm{~mm}$ for test of water absorption rate. The 
specimens were demoulded after 24 hours and immersed into water $\left(20^{\circ} \mathrm{C}\right)$ till testing. The mix compositions of all the concrete specimens are presented in Table 1.

$$
\begin{aligned}
\mathrm{BCA}= & (\text { property value of } \mathrm{NCA} * 0.90) \\
& +(\text { property value of } \mathrm{RCA} * 0.10) .
\end{aligned}
$$

3.3. Tests. Physical and mechanical properties of the RCA as well as the fresh and the hardened concrete properties were evaluated in accordance with the relevant standards. All the performed tests are given in Table 2. The tests performed to evaluate the physical properties of the RCA include bulk density and void ratio, specific gravity and absorption, shape, size, and texture. The toughness and abrasion characteristics of the RCA were examined using the Los Angeles (L.A.) abrasion test. This test provides a good correlation with the actual wear of the aggregate and compressive and flexural strengths of concrete [39]. Though there are other types of tests that can be applied to assess the mechanical properties of aggregates, L.A. abrasion was the only test performed in this experimental work. This is due to the fact that most of the tests are trivial for normal strength concrete since the strength of aggregate is considerably higher than the normal range of concrete strength. It is also impossible to explicitly relate the results (obtained from tests other than L.A. abrasion) with the potential strength development of the concrete. The fresh and the hardened properties of all the concrete specimens were also examined. In the fresh state, the slump test was carried out to assess the workability of the concrete. Examination of the hardened concrete specimens includes compressive strength, splitting tensile strength, and water absorption rate.

\section{Results and Discussion}

4.1. Properties of Aggregates. RCA acquired from crushed concrete waste is normally different from NCA since the original aggregate particles are surrounded by old cement mortar. The presence of the adhered cement mortar makes RCA to yield different physical and mechanical properties than the NCA. The performance of RCA is also varying depending on the quality of the concrete waste in which they are produced from. The most common properties that describe the physical and mechanical properties of RCA and NCA, which are used to produce all the concrete specimens considered in this experimental study, were tested. The test results are given in Table 3, and a detailed explanation regarding the test results are presented in the rest of this section.

4.1.1. Bulk Density. The bulk densities of the RCA and the NCA were determined in compacted and loose conditions. The compacted bulk density for the RCA was $1344 \mathrm{~kg} / \mathrm{m}^{3}$, whereas that for the NCA was $1678 \mathrm{~kg} / \mathrm{m}^{3}$. The loose bulk densities for the RCA and the NCA were $1178 \mathrm{~kg} / \mathrm{m}^{3}$ and $1567 \mathrm{~kg} / \mathrm{m}^{3}$, respectively. It can be noticed from these test values that the compacted and the loose bulk densities of the
RCA are $25 \%$ and $20 \%$ less than those of the NCA, respectively. The higher the bulk density of the coarse aggregate is an indication of the presence of fewer voids to be filled by small particles such as sand and cement. Though the RCA obtained less bulk density compared with the NCA, it is in the range of normal-weight aggregate's bulk density which is typically between $1280 \mathrm{~kg} / \mathrm{m}^{3}$ and $1920 \mathrm{~kg} / \mathrm{m}^{3}$ [40]. The ratio of the loose bulk density to the compacted bulk density of the RCA was 0.88 and the NCA was 0.93 .

4.1.2. Specific Gravity. Specific gravity of aggregate is the ratio of the density of the aggregate to the density of water. This property is usually applied for determining the volume occupied by the aggregate in concrete mix. There are three different types of specific gravities based on how the volume of water permeable voids (or pores) within the aggregates are considered. These are (i) specific gravity (OD): computed on the basis of oven-dry aggregates; (ii) specific gravity (SSD): analysed on the basis of saturated-surface-dry aggregates; and (iii) apparent specific gravity: calculated on the basis of saturated aggregates. The specific gravities (OD, SSD, and apparent) of the RCA were $2.17,2.35$, and 2.63 which are $20 \%, 15 \%$, and $7 \%$ less than that of the NCA, respectively. The test results demonstrated that the specific gravity (OD) of the RCA is close to the minimum specific gravities of conventional aggregates. The most commonly utilized natural aggregates have specific gravities that vary from 2.2 to 3.0 [41]. A low specific gravity may indicate high porosity and thus poor durability and low strength. It also greatly influences the density and strength of concrete. Both values lie in the range where several common types of aggregates usually fall, which is from 0.87 to 0.96 [42]. The void ratios of the RCA and the NCA were also examined in accordance with ASTM C29/C29M. Although RCA has higher bulk density than NCA, the void ratios of both types of coarse aggregates were identical with a value of $38 \%$.

4.1.3. Absorption. The absorption test determines the total pore volume by measuring the amount of water that the aggregate particles can absorb into its pore structure. This is due to the fact that the amount of the absorbed water relies predominantly on the abundance and the continuity of the pores in the aggregate particle. It is one of the most vital properties required for designing concrete mix. The pore structure of aggregate governs the microstructure of the concrete, which in turn influences the fresh and the hardened concrete characteristics. Indeed, it is a well-known fact since about three-quarters of the concrete volume is occupied by aggregates. The conducted absorption test result confirmed that the amount of water absorbed by the RCA was $7.5 \%$, which is 4.2 times higher than that by the NCA utilized in this experimental study. This is a considerable amount, and it probably results from the high absorption property of the hardened porous cement mortar which is adhered in the original aggregate particles. However, they are in the range between 0 and $8 \%$ where absorption capacity of normal-weight aggregates often fall [40]. 
TABle 1: Mix compositions of the concretes.

\begin{tabular}{lcccccccc}
\hline Group & Mix type & Strength class & w/c ratio $(-)$ & Water $\left(\mathrm{kg} / \mathrm{m}^{3}\right)$ & Cement $\left(\mathrm{kg} / \mathrm{m}^{3}\right)$ & $\mathrm{NCA}\left(\mathrm{kg} / \mathrm{m}^{3}\right)$ & $\mathrm{RCA}\left(\mathrm{kg} / \mathrm{m}^{3}\right)$ & $\mathrm{NFA}\left(\mathrm{kg} / \mathrm{m}^{3}\right)$ \\
\hline \multirow{2}{*}{ I } & Ref-I & \multirow{2}{*}{ C25/35 } & \multirow{2}{*}{0.61} & 230.51 & 296.72 & 1260.77 & - & 682.13 \\
& RC-10 & & & 230.51 & 296.72 & 1134.70 & 126.07 & 682.13 \\
& RC-10* & & & 236.00 & 296.72 & 1114.10 & 123.80 & 707.50 \\
\hline \multirow{2}{*}{ II } & Ref-II & \multirow{2}{*}{ C35/45 } & \multirow{2}{*}{0.55} & 212.67 & 329.10 & 1159.90 & - & 743.43 \\
& RC-20 & & & 212.67 & 329.10 & 927.93 & 231.97 & 743.43 \\
\hline
\end{tabular}

TABLE 2: Test methods applied to characterize the aggregate and the fresh and hardened concrete.

\begin{tabular}{|c|c|c|c|}
\hline Test category & Property und & aluation & Standard applied \\
\hline \multirow{13}{*}{ Aggregates (RCA and NCA) } & \multicolumn{3}{|c|}{ Loose } \\
\hline & Bulk density and void ratio & Compacted & ASTM C29/C29M [29] \\
\hline & & Void ratio & \\
\hline & \multirow{5}{*}{ Specific gravity and absorption } & Oven-dry & \multirow{5}{*}{ ASTM C127-12 [30] } \\
\hline & & Saturated-surface-dry & \\
\hline & & Apparent & \\
\hline & & Absorption & \\
\hline & & Shape & \\
\hline & \multirow{4}{*}{ Shape, size, and texture } & Angularity number & \multirow{2}{*}{ BS EN 932-6 [31] } \\
\hline & & Texture & \\
\hline & & Particle-size distribution & ASTM C136-06 [32] \\
\hline & & Fineness modulus & ASTM C125-12a [33] \\
\hline & Toughness and abrasion & L. A. abrasion & ASTM C131-06 [34] \\
\hline \multirow{4}{*}{ Fresh and hardened concretes } & Workability & Slump & ASTM C143/C143M-12 [35] \\
\hline & \multirow{2}{*}{ Mechanical performance } & Compressive strength & ASTM C39/C39M-12a [36] \\
\hline & & Splitting tensile strength & ASTM C496/C496M [37] \\
\hline & Absorption & Rate of absorption & ASTM C1585-11 [38] \\
\hline
\end{tabular}

TABLE 3: Results obtained in characterization of the RCA and NCA.

\begin{tabular}{|c|c|c|c|c|}
\hline Aggregate property under evaluation & & Unit & RCA & NCA \\
\hline \multirow{3}{*}{ Bulk density and void ratio } & Loose bulk density & $\mathrm{kg} / \mathrm{m}^{3}$ & 1178 & 1567 \\
\hline & Compacted bulk density & $\mathrm{kg} / \mathrm{m}^{3}$ & 1344 & 1678 \\
\hline & Void ratio & $\%$ & 38 & 38 \\
\hline \multirow{4}{*}{ Specific gravity and absorption } & Oven-dry specific gravity & - & 2.17 & 2.70 \\
\hline & Saturated-surface-dry specific gravity & - & 2.35 & 2.75 \\
\hline & Apparent specific gravity & - & 2.63 & 2.83 \\
\hline & Absorption & $\%$ & 7.5 & 1.78 \\
\hline \multirow{5}{*}{ Shape, size, and texture } & Shape & - & Angular & Angular \\
\hline & Angularity number & - & 5 & 5 \\
\hline & Nominal maximum size & $\mathrm{mm}$ & 37.5 & 37.5 \\
\hline & Fineness modulus & - & 1.48 & 2.42 \\
\hline & Texture & - & Rough & Rough \\
\hline Toughness and abrasion & L. A. abrasion loss & $\%$ & 32.88 & 19.11 \\
\hline
\end{tabular}

4.1.4. Shape, Size, and Texture. The shape and surface texture properties of the employed aggregates were determined in accordance with BS EN 932-6 [31]. These characteristics of the aggregate control the performance of the concrete. The shapes and textures of the RCA and the NCA used in this experimental work were visually assessed. The representative samples of the RCA and the NCA particles are shown in Figure 1. Both types of the coarse aggregates were identified as angular in shape with an angularity number of 5 . Since the RCA and the NCA have identical void ratios, they obtained the same angularity numbers. The computed angularity numbers lie in the range where the conventional aggregates usually fall (0 to 11) [42]. The surface texture of the RCA was rougher than the NCA. Rough coarse aggregate normally causing high percentage of voids between particles which affects the amount of cement paste is required for the concrete mix. However, as presented in the Section 4.1.2, both types of aggregates yield the same void ratios.

The sieve analysis was carried out to examine the size distribution of all the utilized aggregates using sieve sizes which are normally applied for grading purpose in accordance with ASTM C136-06 [32]. Grading of aggregates is mainly needed to produce concrete with a reasonable workability and minimum segregation. Figure 2 illustrates 


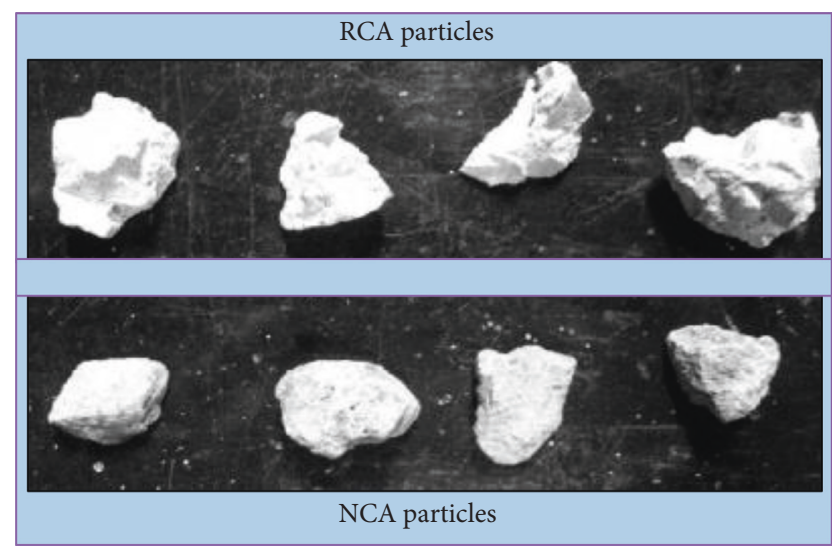

FIGURE 1: Representative sample of the RCA and the NCA particles exhibiting their shapes.

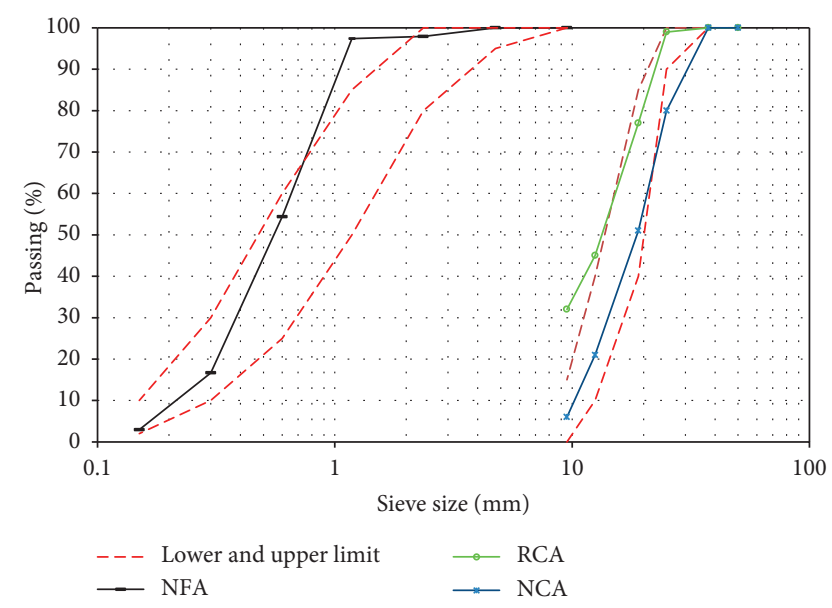

FIgUre 2: Grading chart of the fine aggregate, RCA, and NCA. Dashed lines indicate limits specified in ASTM C33/C33M.

the cumulative percentage passing versus the logarithmic sieve size for the NFA, NCA, and RCA together with the corresponding grading limits specified by ASTM C33/C33M-11 [43]. It can be observed that all types of aggregates are not fully in the grading limits. Indeed, there is no ideal grading because of the interacting influences on the main factors that governs workability of fresh concrete such as the surface area of the aggregate particles and the amount of fines in the mix [42]. Though both types of aggregates disobey with the limits set in ASTM C33/C33M-11, they were utilized to produce concrete specimens. After completing the sieve analysis, the fineness modulus and the nominal maximum size of the coarse aggregates were determined. The fineness modulus for the NCA was 2.42, while for the RCA, it was 1.48, and it is out of the typical range where the conventional aggregates often lie which is from 2.3 to 3.0 [42]. The higher the fineness modulus value of the NCA indicates that its grading is coarser than the RCA. This fact can also be noticed from Figure 2. The nominal maximum sizes of the RCA and the NCA were determined according to ASTM C125-12a [33]. Both types of aggregates yield $37.5 \mathrm{~mm}$ which is the maximum limit for nominal maximum size of typical normal-weight coarse aggregate used for concrete production [40].

4.1.5. Toughness and Abrasion. The toughness and abrasion characteristics of the RCA and the NCA were evaluated by the L.A. abrasion test in accordance with ASTM C131-06. This test combines the processes of attrition and abrasion and provides results which indicate a correlation with the actual wear of the aggregate. A sample of aggregate particles retained on the sieve size recommended by the standard was placed inside a rotating steel drum which contains a specified number of steel spheres. As the drum rotates, the aggregate particles are subjected to abrasion and grinding. The drum continues to rotate for a specified number of revolutions. Then after, the aggregate was removed from the drum and sieved using the same sieve. The aggregate retained on the sieve was weighed, and the difference between this weight and the original weight was expressed as a percentage to obtain the L.A. abrasion loss. The value of the L.A. abrasion loss of the NCA was $19.11 \%$, whereas the RCA was $32.88 \%$. It means that the RCA has poorer resistance to abrasion than the NCA used in the work. The L.A. abrasion loss of the RCA is slightly higher than the acceptable limit set in BS EN 12620:2002+A1:2008 [44] for wearing surfaces which is $30 \%$. However, it is suitable for general construction since its L.A. abrasion loss is well under the upper limit (45\%) specified by BS EN 12620:2002+A1:2008 [44] and ASTM C33/C33M-11 (50\%) [43].

\subsection{Fresh and Hardened Concrete Properties}

4.2.1. Workability. The consistency of all the fresh concrete mixes was measured in laboratory, to check the workability, using the slump test. The slumps of the concrete mixes are given in Table 4 . It can be observed that the slumps of RC-10 and RC-20 were dropped by $2 \mathrm{~mm}$ and $3 \mathrm{~mm}$ compared with their corresponding control concrete mixes (Ref-I and RefII), respectively. This means that the workability degrees of RC-10 and RC-20 are slightly lower than their corresponding reference concretes. It is obvious that workability of fresh concrete relies on a number of interacting factors such as water content, aggregate type, and grading. The water content of the concrete mix is the most predominant factor. However, this is not the case for dropping the slumps of RC-10 and RC-20 since the water contents of both mixes were identical with their corresponding control mixes as seen in Table 1.

The volumetric ratio of the coarse aggregates to cement content as well as the volumetric ratio of the coarse aggregates to the fine aggregates was computed to get insight into what controls the workability. The computed ratios are given in Table 4 . The volumetric ratio of the coarse aggregates to the cement content for RC-10 was 0.77 and for RC20 was 0.73 , surpassing their corresponding reference mixes by $2.67 \%$ and $5.80 \%$, respectively. The volumetric ratios of the coarse aggregates to the fine aggregate of RC-10 and RC20 also exceed the reference mixes Ref-I and Ref-II by $2.60 \%$ 
TABLE 4: Slump and volumetric ratios of coarse aggregates to cement content and coarse aggregates to fine aggregates of the concretes.

\begin{tabular}{lccccc}
\hline Group & Mix type & Slump (mm) & w/c (-) & $\begin{array}{c}\text { Volumetric ratio of coarse } \\
\text { aggregates to cement content (-) }\end{array}$ & $\begin{array}{c}\text { Volumetric ratio of coarse } \\
\text { aggregates to the fine aggregates (-) }\end{array}$ \\
\hline \multirow{2}{*}{ I } & Ref-I & 17 & & 0.75 & 1.54 \\
& RC-10 & 15 & 0.61 & 0.77 & 1.58 \\
\hline \multirow{2}{*}{ II } & RC-10* & 25 & & 0.76 & 1.50 \\
& Ref-II & 18 & \multirow{2}{*}{0.55} & 0.69 & 1.56 \\
\hline
\end{tabular}

and $5.13 \%$, respectively. This increment in volumetric ratios (coarse aggregates to cement content and coarse aggregates to fine aggregates) is due to the low bulk density characteristic of the utilized RCA. The increment in volumetric ratios reveals that the amount of water relative to the total surface of the solid particles is smaller for RC-10 and RC-20 compared with their corresponding control mixes. In other words, when the NCA is partially replaced by the RCA, the concrete mix demands additional water to achieve a similar level of workability as of the concrete prepared with only natural aggregates. Workability of concrete can also be considerably affected by the shape of the coarse aggregates. It decreases when the angularity number of the coarse aggregates increases [42]. However, in this experimental work, the shape of the RCA applies no effect on the slump of the concrete mixes (which employed RCA) since both types of coarse aggregates obtained the same angularity number. All these facts confirmed that the drop of the slumps of RC-10 and RC-20 is due to the low bulk density and the roughened surface texture properties of the employed RCA.

The slump of RC- $10^{*}$ was $25 \mathrm{~mm}$ that exceeds the reference mix by $8 \mathrm{~mm}$. The volumetric ratios of the coarse aggregates to the cement content and the coarse aggregates to the fine aggregates were also computed for this mix. The former exceeds by $1.33 \%$ but the latter lessens by $2.6 \%$ compared with the control mix, Ref-I. This demonstrates that the assumption considered for estimating the value of properties of the blended coarse aggregates (Equation (1)) to design the concrete mix RC-10* was impractical. Though there is generally a noticeable change in the slump value when the NCA is replaced by the RCA, all the concrete mixes obtained very low workability. The degree of workability is considered to be very low when the slump of fresh concrete falls in the range between 0 and $25 \mathrm{~mm}$ [42].

4.2.2. Compressive Strength. Compressive strength is the foremost mechanical property of concrete that provides a general idea regarding the quality of concrete since it is directly related to the structure of the hydrated cement paste. The compressive strength of all the concrete specimens categorized in Group I is illustrated in Figure 3. Figure 4 shows the compressive strength of the hardened concrete specimens categorized in Group II. It can be apparently seen from both figures that there is a clear trend of increase in compressive strength with the age of the concrete. Indeed, it is the expected result. It can also be observed that all the concrete specimens attained the targeted compressive strength at the age of 28 days: $25 \mathrm{MPa}$ for Group I (Ref-I, RC10 , and RC-10*) and $35 \mathrm{MPa}$ for Group II (Ref-II and RC-

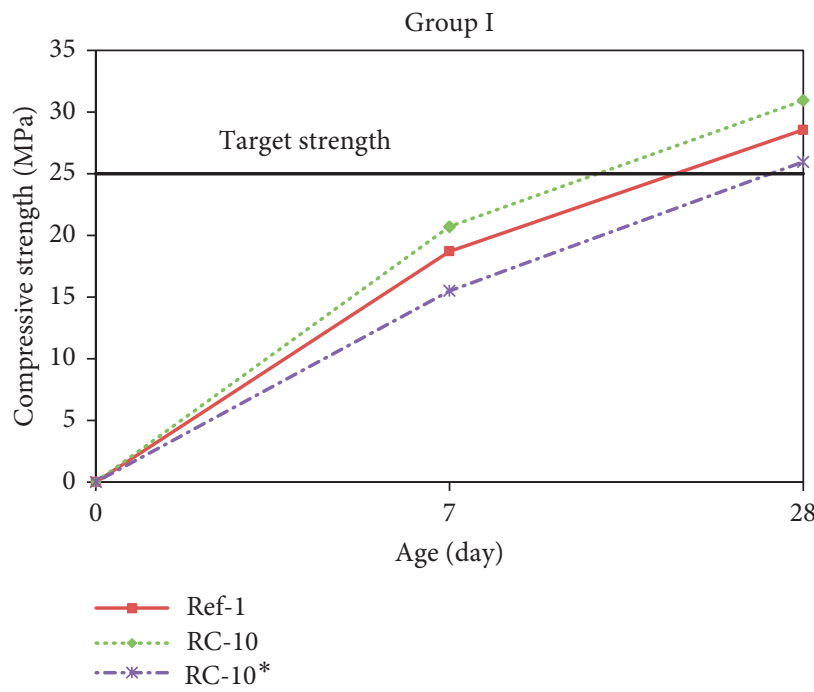

Figure 3: Compressive strength of the concrete specimens categorized in Group I.

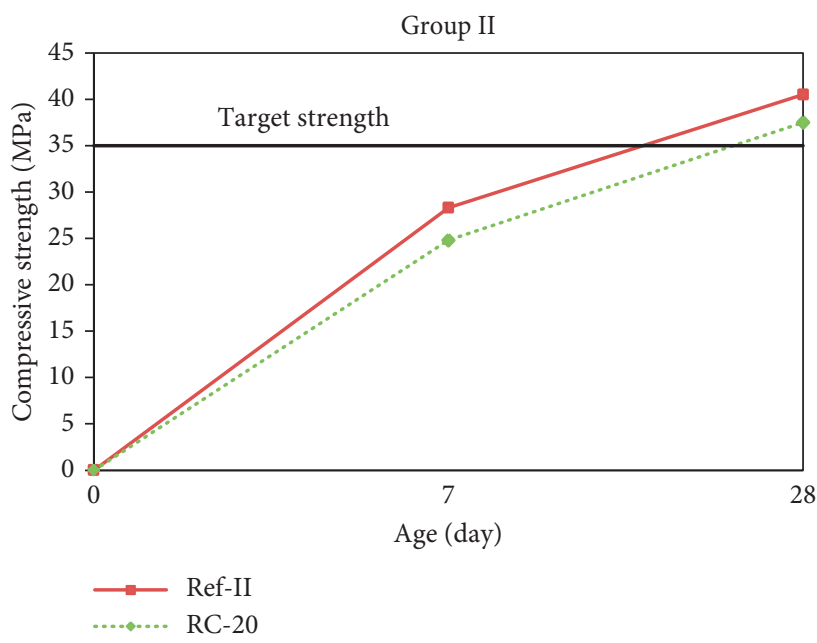

FIGURE 4: Compressive strength of the concrete specimens categorized in Group II.

20). The compressive strength of all the concrete specimens at the age of 7 and 28 days is given in Table 5 .

The compressive strength of RA-10 is $11 \%$ and $8 \%$ more than the corresponding reference concrete (Ref-I) at the age of 7 and 28 days, respectively. However, the compressive strength of RC-20 is lower than the corresponding control concrete mix (Ref-II) by $12 \%$ and $7 \%$ at the age of 7 and 28 
TABle 5: Compressive strength and splitting tensile strength at different ages of concrete specimens.

\begin{tabular}{lccccc}
\hline Group & Mix type & $\begin{array}{c}\text { Strength } \\
\text { class }\end{array}$ & \multicolumn{2}{c}{ Compressive } \\
strength (MPa) & $\begin{array}{c}\text { Splitting tensile } \\
\text { strength (MPa) }\end{array}$ \\
& & & 7 days & 28 days & 28 days \\
\hline \multirow{2}{*}{ I } & Ref-I & & 18.70 & 28.55 & 3.05 \\
& RC-10 & \multirow{2}{*}{ C25/35 } & 20.70 & 30.95 & 3.05 \\
& RC-10* & & 15.50 & 25.95 & 2.64 \\
\hline \multirow{2}{*}{ II } & Ref-II & \multirow{2}{*}{ C35/45 } & 28.30 & 40.50 & 3.19 \\
& RC-20 & & 24.80 & 37.50 & 3.05 \\
\hline
\end{tabular}

days, respectively. In the case of $\mathrm{RC}-10^{*}$, the compressive strength is diminished by $17 \%$ and $9 \%$ at the age of 7 and 28 days compared with the compressive strength of the reference mix (Ref-1), respectively. During designing of RC-10*, the physical properties of the blended coarse aggregates were estimated using Equation (1). The characteristics of the fresh and hardened concretes of RC-10* and Ref-I were expected to be nearly identical. But, the test result shows that the assumption was impractical. Even if the concrete mix type of RC$10^{*}$ and RC-20 obtained less compressive strength, they attained the desired strength at the age of 28 days with the compressive strength of $25.95 \mathrm{MPa}$ and $37.50 \mathrm{MPa}$, respectively.

Despite the fact that the utilized RCA has inferior physical and mechanical properties compared with the NCA, the replacement of $10 \%$ of the total NCA by the RCA enhances the compressive strength of the hardened concrete. Even, the variation in compressive strength of RC-20 compared with the control mix is insignificant. Indeed, the effect of RCA on characterizing compressive strength development of hardened concrete is controversial. There are earlier researches that concluded partial replacement of NCA by RCA affects the compressive strength of concrete adversely $[45,46]$. On the contrary, there are studies which revealed that compressive strength of concrete produced from a blend of NCA and RCA (even with $>10 \%$ proportion) has higher compressive strength at the age of 28 days than that of the concretes utilized only NCA [47-49]. The findings of this work agree with the later studies. The most plausible reason for the compressive strength improvement of RC-10 is the shape and the surface texture of the employed RCA. The shape of the RCA was angular, and its surface texture was rough. Normally angular aggregates with rough surface texture result in a strong bond between the particles and the cement matrix, thus contributing towards the development of the strength. The quality of the concrete waste from which the utilized RCA was produced may also contribute for achieving high compressive strength. It is persuasive that the strength of the original concrete is high since it was used as a machine foundation. In addition, the RCA was obtained from a concrete waste of a homogenous source with less impurity as confirmed by the specific gravity test results.

4.2.3. Splitting Tensile Strength. The splitting tensile strength test was carried out at the age of 28 days according to ASTM C496/C496M as seen in Figure 5. The test results are given in Table 5 . It can be apparently seen from Table 5 that the

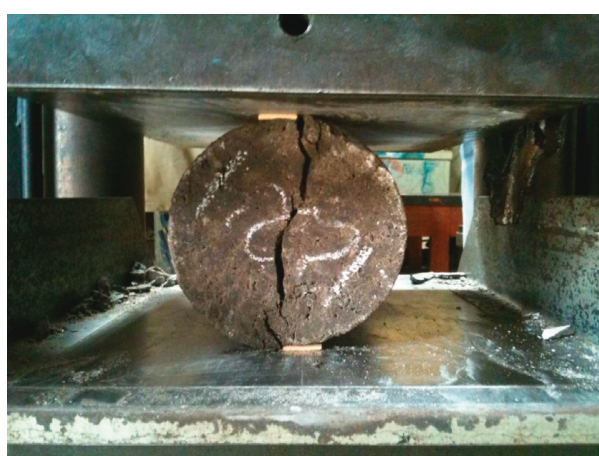

FIGURE 5: Performing splitting tensile strength test at the MRTC of the EiABC, Addis Ababa University.

splitting tensile strength of RC-10 is $3.05 \mathrm{MPa}$, and it is similar to the reference concrete of Group I (Ref-I). But, in the case of $\mathrm{RC}-10^{*}$, reduction of $13 \%$ in splitting tensile strength was observed with the value of 2.64 MPa. As of the other tests, the finding of this property test confirms that the assumption made for designing RC-10* was incorrect. In Group II, the splitting tensile strength of RC-20 was 3.05 MPa, whereas for the reference concrete (Ref-II), it was $3.19 \mathrm{MPa}$. This means that the reduction in splitting tensile strength due to the $20 \%$ replacement of the NCA by RCA is only about $4 \%$. It can be concluded that the variation between the splitting tensile strength of concrete mixes which employ RCA and conventional aggregate is insignificant. This finding is also supported by earlier researches $[50,51]$.

4.2.4. Water Absorption Rate. The water absorption rates (sorptivity) of all the concrete mixes were tested in accordance with ASTM C1585-11. This test method determines the sorptivity of water by exposing the bottom surface of the specimen to liquid water and measuring the increase in the mass of a specimen resulting from water absorption as a function of time. The side surface of the specimens was sealed with a sealing material. Also, all the ends of the specimens (excluding the bottom) were sealed using a loosely attached plastic sheet as stated in ASTM C1585-11. The sorptivity test normally involves recording incremental mass change measurements (after the specimen being in contact with water) at relatively frequent intervals during the first 6 hours and every single day for the next 8 days. Then, the amount of absorbed water will be computed, which is the change in mass divided by the product of the cross-sectional area of the test specimen and the density of water.

The amount of absorbed water by all the concrete specimens as a function of the square root of time is plotted in Figure 6. The slope of the curve of the first 6 hour represents the initial sorptivity, whereas that from 1 to 8 days represents the secondary sorptivity. The initial sorptivity and secondary sorptivity of all the concrete mixes are given in Table 6 along with the coefficient of determination $\left(R^{2}\right)$. The $R^{2}$ values for all concrete specimens are well above 0.90 , indicating the degree of accuracy of the determined slopes. It can be clearly observed from Table 6 that the sorptivity (in initial and secondary phases) of the concrete specimens 


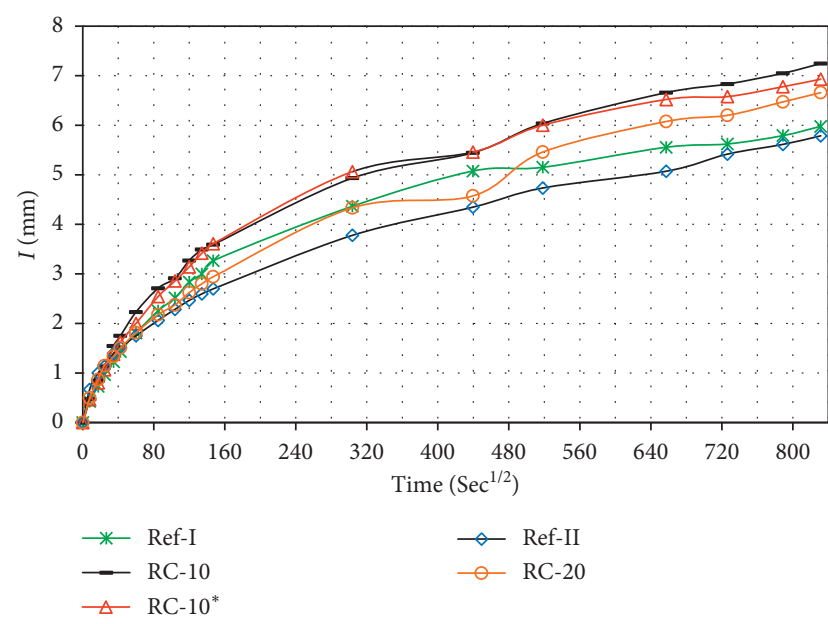

FIgURE 6: The amount of absorbed water by the concrete specimens versus square root of time.

TABLE 6: Sorptivity and cumulative sorption of all concrete specimens.

\begin{tabular}{|c|c|c|c|c|c|}
\hline \multirow[b]{2}{*}{$\begin{array}{l}\text { Concrete } \\
\text { mix type }\end{array}$} & \multicolumn{2}{|c|}{ Initial phase } & \multicolumn{2}{|c|}{ Secondary phase } & \multirow{2}{*}{$\begin{array}{l}\text { Cumulative } \\
\text { sorption } \\
(\mathrm{mm})\end{array}$} \\
\hline & $\begin{array}{l}\text { Sorptivity } \\
\left(\mathrm{mm} / \mathrm{s}^{1 / 2}\right)\end{array}$ & $R^{2}(-)$ & $\begin{array}{l}\text { Sorptivity } \\
\left(\mathrm{mm} / \mathrm{s}^{1 / 2}\right)\end{array}$ & $R^{2}(-)$ & \\
\hline Ref-I & $20.6 \times 10^{-3}$ & 0.98 & $2.7 \times 10^{-3}$ & 0.96 & 5.98 \\
\hline RC-10 & $23.2 \times 10^{-3}$ & 0.96 & $4.4 \times 10^{-3}$ & 0.99 & 7.24 \\
\hline $\mathrm{RC}-10^{*}$ & $23.1 \times 10^{-3}$ & 0.98 & $3.6 \times 10^{-3}$ & 0.98 & 6.93 \\
\hline Ref-II & $15.5 \times 10^{-3}$ & 0.92 & $3.7 \times 10^{-3}$ & 0.99 & 5.79 \\
\hline $\mathrm{RC}-20$ & $17.8 \times 10^{-3}$ & 0.94 & $4.6 \times 10^{-3}$ & 0.96 & 6.66 \\
\hline
\end{tabular}

which employed RCA is higher than those made with only conventional aggregates. The cumulative sorption, after eight days of continuous exposure to water, of all the concrete specimens is also given in the same table. It can be noticed that partial replacement of the NCA by the RCA affects the water absorption property of the concrete adversely. The cumulative sorption for RC-10 was $7.24 \mathrm{~mm}$, while for Ref-I, it was $5.98 \mathrm{~mm}$. This means that $10 \%$ replacement of the NCA by the RCA is caused for $21 \%$ increment in cumulative sorption. The cumulative sorption of RC-20 was higher by $15 \%$ compared with the corresponding control mix (Ref-II). In fact, all these results were expected since the absorption capacity of the utilized RCA is 4.2 times higher than that of the NCA used in this experimental study. All these results indicate that concrete made with RCA has a lower resistance against penetration of water and other aggressive substances into the concrete pores than is the case of concrete made with only natural aggregates.

\section{Conclusions}

In this work, the physical and mechanical properties of RCA produced from concrete waste were examined and compared with the NCA utilized in the experimental study. The RCA showed relatively lower physical and mechanical properties compared with the NCA. However, in many cases, the physical properties of the RCA were in the typical range of normal-weight aggregates. The toughness and abrasion characteristics of the RCA comply with the criterion set for general construction as of the NCA. The workability, strength, and permeability aspects of the concrete specimens which employed the RCA were also studied thoroughly and compared with the corresponding control mix made with natural aggregates. The workability of the fresh concrete which employs the RCA was slightly lower than the concrete produced from conventional aggregates. Concrete that utilized $10 \%$ of the RCA had a higher compressive strength than concrete that employed only natural aggregates. The splitting tensile strength of the concrete specimens which employ RCA up to $20 \%$ was comparable with that of the concrete made with natural aggregates. The absorption rate of the hardened concrete specimens that utilized RCA was higher than those specimens employed only conventional aggregates.

All the test results of this experimental study confirm that RCA produced by crushing concrete waste manually can be utilized in construction industry. As the experiment was performed in Ethiopia using local knowledge and technology, it will trigger construction industries or construction material manufacturers of the local to recycle concrete waste for production of new concrete or other construction materials instead of disposing to landfill. This will bring huge economic and environmental advantages to the society as it greatly helps us to conserve natural resources and reduce waste disposal and haul, as well as increasing employment. In addition, the results of this study serve as a show case for research institutes or construction industries of emerging countries to carry out similar experiments on different types of CDW since comprehensive studies in the context of developing countries is missing.

\section{Data Availability}

The data used to support the findings of this study are available from the corresponding author upon request.

\section{Conflicts of Interest}

The author declares that there are no conflicts of interest.

\section{Acknowledgments}

The author gratefully acknowledges the technical staff of the Materials Research and Testing Center (MRTC) of Ethiopian Institute of Architecture, Building Construction and City Development (EiABC), Addis Ababa University for their support during preparation and testing of the concrete specimens.

\section{References}

[1] D. Hoornweg and P. Bhada-Tata, What a Waste: A Global Review of Solid Waste Management, World Bank, Washington, DC, USA, 2012.

[2] C. Rodríguez, C. Parra, G. Casado et al., "The incorporation of construction and demolition wastes as recycled mixed aggregates in non-structural concrete precast pieces," Journal of Cleaner Production, vol. 127, pp. 152-161, 2016. 
[3] M. Mália, J. de Brito, M. D. Pinheiro, and M. Bravo, "Construction and demolition waste indicators," Waste Management and Research, vol. 31, no. 3, pp. 241-255, 2013.

[4] A. S. M. A. Awal and H. Mohammadhosseini, "Green concrete production incorporating waste carpet fiber and palm oil fuel ash," Journal of Cleaner Production, vol. 137, pp. 157-166, 2016.

[5] B. J. Zhan and C. S. Poon, "Study on feasibility of reutilizing textile effluent sludge for producing concrete blocks," Journal of Cleaner Production, vol. 101, pp. 174-179, 2015.

[6] S. Hesami, I. S. Hikouei, and S. A. A. Emadi, "Mechanical behavior of self-compacting concrete pavements incorporating recycled tire rubber crumb and reinforced with polypropylene fiber," Journal of Cleaner Production, vol. 133, pp. 228-234, 2016.

[7] B. S. Thomas and R. C. Gupta, "Properties of high strength concrete containing scrap tire rubber," Journal of Cleaner Production, vol. 113, pp. 86-92, 2016.

[8] F. Faleschini, M. A. Fernández-Ruíz, M. A. Zanini, K. Brunelli, C. Pellegrino, and E. Hernández-Montes, "High performance concrete with electric arc furnace slag as aggregate: mechanical and durability properties," Construction and Building Materials, vol. 101, pp. 113-121, 2015.

[9] F. Faleschini, M. A. Zanini, K. Brunelli, and C. Pellegrino, "Valorization of co-combustion fly ash in concrete production," Materials and Design, vol. 85, pp. 687-694, 2015.

[10] H. A. Alaka and L. O. Oyedele, "High volume fly ash concrete: the practical impact of using superabundant dose of high range water reducer," Journal of Building Engineering, vol. 8, pp. 81-90, 2016.

[11] W.Z. Taffese, "Low-cost eco-friendly building material : a case study in Ethiopia," International Journal of Civil, Environmental, Structural, Construction and Architectural Engineering, vol. 6, pp. 183-187, 2012, http://scholar.waset.org/1307$6892 / 7965$.

[12] X. Zhou, F. Zheng, H. Li, and C. Lu, "An environmentfriendly thermal insulation material from cotton stalk fibers," Energy and Buildings, vol. 42, no. 7, pp. 1070-1074, 2010.

[13] M. Kuhar, World Aggregates Market, SEMCO Publishing, Denver, CO, USA, 2014, http://www.rockproducts.com/ features/13045-world-aggregates-market.html\#.WjFB$\mathrm{zdx} 3 \mathrm{cs}$.

[14] M. D. Yehualaw and A. K. Woldesenbet, "Economic impacts of recycled concrete aggregate for developing nations: a case study in the Ethiopian construction industry," in Proceedings of Construction Research Congress 2016, pp. 250-259, American Society of Civil Engineers, San Juan, PR, USA, June 2016.

[15] F. Özalp, H. DilşadYılmaz, M. Kara, Ö. Kaya, and A. Şahin, "Effects of recycled aggregates from construction and demolition wastes on mechanical and permeability properties of paving stone, kerb and concrete pipes," Construction and Building Materials, vol. 110, pp. 17-23, 2016.

[16] M. N. Soutsos, K. Tang, and S. G. Millard, "Concrete building blocks made with recycled demolition aggregate," Construction and Building Materials, vol. 25, no. 2, pp. 726-735, 2011.

[17] B. S. Hamad and A. H. Dawi, "Sustainable normal and high strength recycled aggregate concretes using crushed tested cylinders as coarse aggregates," Case Studies in Construction Materials, vol. 7, pp. 228-239, 2017.

[18] C.-S. Poon, S. Kou, H. Wan, and M. Etxeberria, "Properties of concrete blocks prepared with low grade recycled aggregates," Waste Management, vol. 29, no. 8, pp. 2369-2377, 2009.
[19] S. Manzi, C. Mazzotti, and M. C. Bignozzi, "Self-compacting concrete with recycled concrete aggregate: study of the longterm properties," Construction and Building Materials, vol. 157, pp. 582-590, 2017.

[20] M. Etxeberria, A. R. Marí, and E. Vázquez, "Recycled aggregate concrete as structural material," Materials and Structures, vol. 40, no. 5, pp. 529-541, 2007.

[21] N. Tošić, S. Marinković, T. Dašić, and M. Stanić, "Multicriteria optimization of natural and recycled aggregate concrete for structural use," Journal of Cleaner Production, vol. 87, pp. 766-776, 2015.

[22] C. Thomas, J. Setién, J. A. Polanco, P. Alaejos, and M. S. de Juan, "Durability of recycled aggregate concrete," Construction and Building Materials, vol. 40, pp. 1054-1065, 2013.

[23] F. Faleschini, M. A. Zanini, and L. Hofer, "Reliability-based analysis of recycled aggregate concrete under carbonation," Advances in Civil Engineering, vol. 2018, Article ID 4742372, 11 pages, 2018.

[24] M. Wijayasundara, P. Mendis, and R. H. Crawford, "Methodology for the integrated assessment on the use of recycled concrete aggregate replacing natural aggregate in structural concrete," Journal of Cleaner Production, vol. 166, pp. 321334, 2017.

[25] S.-S. Park, S.-J. Kim, K. Chen, Y.-J. Lee, and S.-B. Lee, "Crushing characteristics of a recycled aggregate from waste concrete," Construction and Building Materials, vol. 160, pp. 100-105, 2018.

[26] M. Bravo, J. de Brito, J. Pontes, and L. Evangelista, “Durability performance of concrete with recycled aggregates from construction and demolition waste plants," Construction and Building Materials, vol. 77, pp. 357-369, 2015.

[27] W. Z. Taffese, "Assessing suitability of recycled aggregate for use in concrete," in Proceedings of National Conference on Science, Technology, and Innovation for Prosperity of Ethiopia, pp. 134-137, Institute of Technology, Bahir Dar University, Bahir Dar, Ethiopia, May 2012.

[28] W. Z. Taffese, "Effect of recycled coarse aggregate on concrete properties," in Proceedings of International Conference of Advances in Cement and Concrete Technology in Africa, pp. 1007-1014, BAM Federal Institute for Materials Research and Testing, Johannesburg, South Africa, January 2013.

[29] ASTM C29/C29M, Standard Test Method for Bulk Density (Unit Weight) and Voids in Aggregate, ASTM, West Conshohocken, PA, USA, 2009.

[30] ASTM C127-12, Standard Test Method for Density, Relative Density (Specific Gravity), and Absorption of Coarse Aggregate, ASTM, West Conshohocken, PA, USA, 2012.

[31] BS EN 932-1:1997, Tests for General Properties of Aggregates. Methods for Sampling, 1997.

[32] ASTM C136-06, Standard Test Method for Sieve Analysis of Fine and Coarse Aggregates, ASTM, West Conshohocken, PA, USA, 2006.

[33] ASTM C125-12a, Standard Terminology Relating to Concrete and Concrete Aggregates, ASTM, West Conshohocken, PA, USA, 2012.

[34] ASTM C131-06, Standard Test Method for Resistance to Degradation of Small-Size Coarse Aggregate by Abrasion and Impact in the Los Angeles Machine, ASTM, West Conshohocken, PA, USA, 2006.

[35] ASTM C143/C143M-12, Standard Test Method for Slump of Hydraulic-Cement Concrete, ASTM, West Conshohocken, PA, USA, 2012. 
[36] ASTM C39/C39M-12a, Standard Test Method for Compressive Strength of Cylindrical Concrete Specimens, ASTM, West Conshohocken, PA, USA, 2012.

[37] ASTM C496/C496M, Standard Test Method for Splitting Tensile Strength of Cylindrical Concrete Specimens, ASTM, West Conshohocken, PA, USA, 2011.

[38] ASTM C1585-11, Standard Test Method for Measurement of Rate of Absorption of Water by Hydraulic-Cement Concretes, ASTM, West Conshohocken, PA, USA, 2011.

[39] A. M. Neville, Properties of Concrete, Pearson, London, UK, 5th edition, 2011.

[40] ACI Committee E701, Aggregates for Concrete, ACI, Farmington Hills, MI, USA, 2016.

[41] M. Alexander and S. Mindess, Aggregates in Concrete, Taylor and Francis, Abingdon, UK, 2005.

[42] A. M. Neville and J. J. Brooks, Concrete Technology, Prentice Hall, Bergen, NJ, USA, 2nd edition, 2010.

[43] ASTM C33/C33M-11, Standard Specification for Concrete Aggregates, ASTM, West Conshohocken, PA, USA, 2011.

[44] BS EN 12620:2002+A1:2008, Aggregates for Concrete, 2002.

[45] S. Mandal and A. Gupta, "Strength and durability of recycled aggregate concrete," IABSE Symposium Report, vol. 86, no. 6, pp. 33-46, 2002.

[46] J. Sharma and S. Singla, "Influence of recycled concrete aggregates on strength parameters of concrete," SSRG International Journal of Civil Engineering, vol. 1, no. 4, pp. 20-24, 2014.

[47] M. Surya, V. Kanta Rao, and P. Lakshmy, "Recycled aggregate concrete for transportation infrastructure," Procedia-Social and Behavioral Sciences, vol. 104, pp. 1158-1167, 2013.

[48] P. C. Yong and D. C. L. Teo, "Utilisation of recycled aggregate as coarse aggregate in concrete," Journal of Civil Engineering, Science and Technology, vol. 1, no. 1, 2009.

[49] N. Y. Ho, Y. P. K. Lee, W. F. Lim et al., "Efficient utilization of recycled concrete aggregate in structural concrete," Journal of Materials in Civil Engineering, vol. 25, no. 3, pp. 318-327, 2013.

[50] M. Safiuddin, U. J. Alengaram, M. A. Salam, M. Z. Jumaat, F. F. Jaafar, and H. B. Saad, "Properties of high-workability concrete with recycled concrete aggregate," Materials Research, vol. 14, no. 2, pp. 248-255, 2011.

[51] T. Kang, W. Kim, Y.-K. Kwak, and S.-G. Hong, "The choice of recycled concrete aggregates for flexural members," IABSE Congress Report, vol. 18, no. 21, pp. 726-731, 2012. 


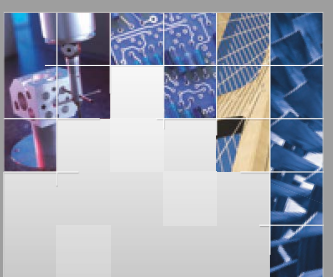

\section{Enfincering}
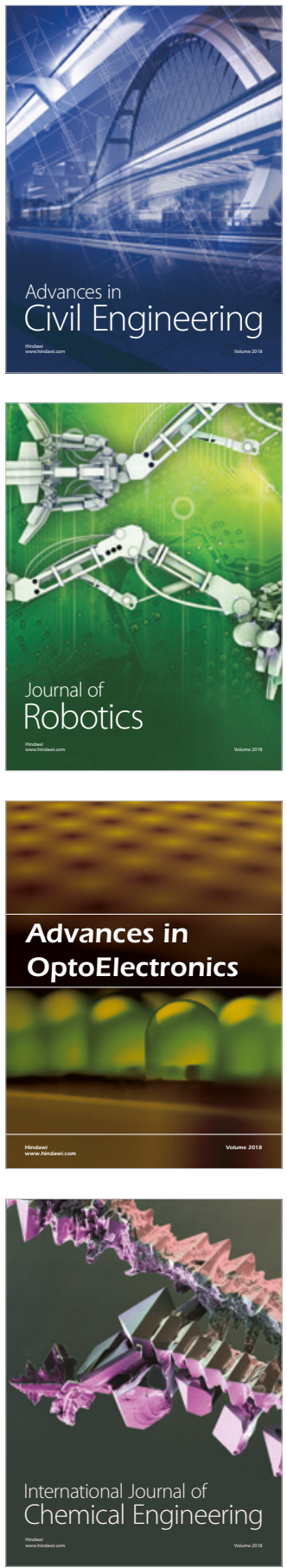

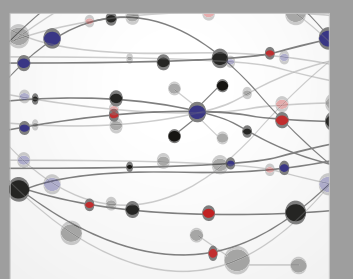

\section{Rotating \\ Machinery}

The Scientific World Journal

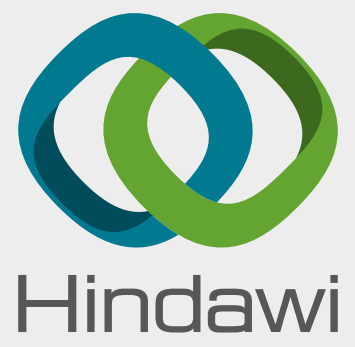

Submit your manuscripts at

www.hindawi.com
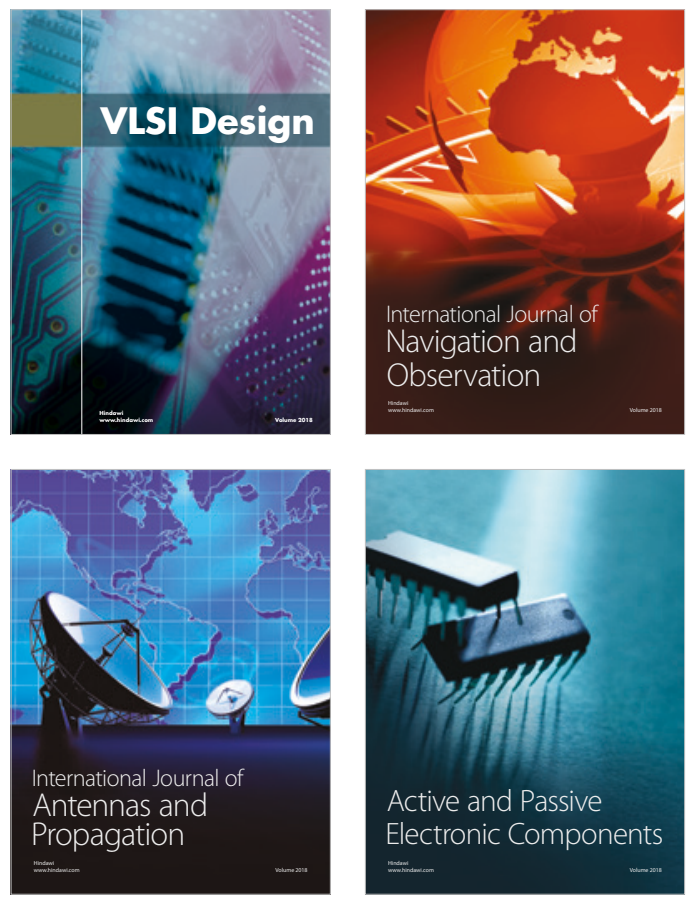
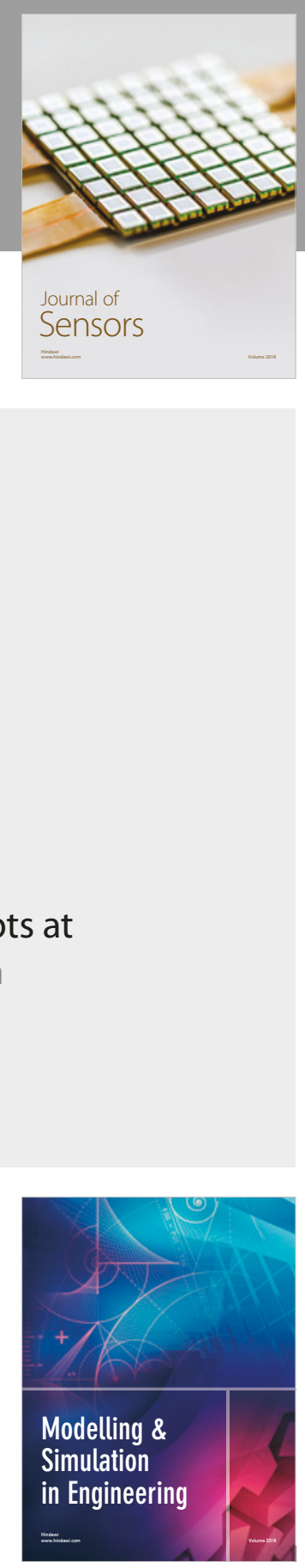

\section{Advances \\ Multimedia}
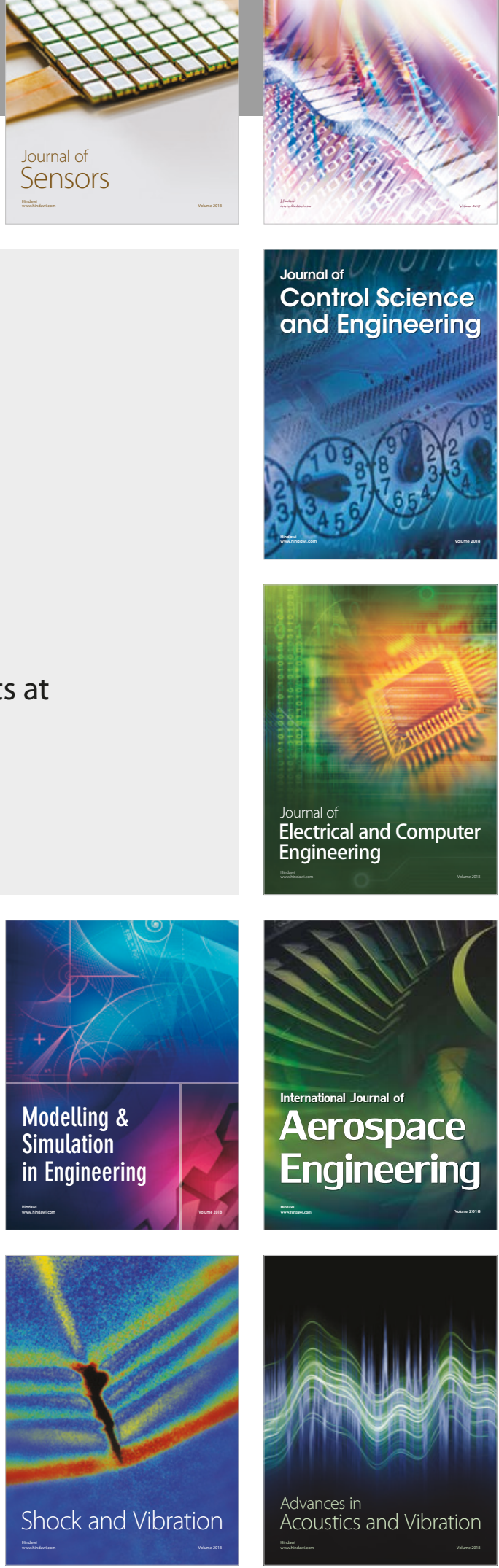